\title{
ESTETIKA PADUAN SUARA DRAMA MUSIKAL ABU DZAR AL GHIFARI
}

\author{
Welly Suryandoko \\ Prodi Pendidikan Sendratasik, FBS, Universitas Negeri Surabaya \\ Email: wellysuryandoko@unesa.ac.id
}

\begin{abstract}
The musical drama element consists of dance and music drama. Each of these variables becomes a reinforcing dimension in a musical drama show. Including music, in addition to instruments that can produce illustrated music in certain scenes or a certain atmosphere. Choir in Abu Dzar Al Ghifari's Musical Drama as a plot driver. The role of the choir in this performance is a) The dimension of the choir's role is divided into three things 1) the choir as an actor, 2) the choir as an event reinforcer, 3) the choir as the ideal audience, 3) the choir and dance moves. b) Choir aesthetics are divided into five things 1) soloists in choirs, 2) choir opening songs, 3) ambience songs, 4) climax songs, and 5) ending songs of musicals. The above perspective was examined using aesthetic studies to analyze the Musical Drama Abu Dhar Al Ghifari Choir which tells the heroic story of the characters in the time of Rosulullah Muhammad SAW. Through this analysis will be produced a spectrum of aesthetic Choirs in Musical Drama.
\end{abstract}

Key Words: aesthetics, choir, musical drama

\begin{abstract}
Abstrak: Unsur Drama Musikal terdiri dari drama tari dan musik. Masing-masing variabel tersebut menjadi dimensi penguat dalam pertunjukan Drama Musikal. Termasuk musik, selain instrumen yang dapat menghasilkan musik ilustrasi pada adegan tertentu atau suasana adengan tertentu. Paduan suara dalam Drama Musikal Abu Dzar Al Ghifari sebagai penggerak plot. Peranan paduan suara dalam pertunjukan ini adalah a) Dimensi peran paduan suara terbagi menjadi empat hal 1) paduan suara sebagai aktor, 2) paduan suara sebagai penguat peristiwa, 3) paduan suara sebagai penonton ideal, 4) paduan suara dan gerak tari. b) Estetika paduan suara terbagi menjadi lima hal 1) solois dalam paduan suara, 2) lagu pembuka paduan suara, 3) lagu adengan suasana, 4) lagu klimaks, dan 5) lagu penutup drama musikal. Perspektif diatas dikaji menggunakan kajian estetika untuk menganalisis Paduan Suara Drama Musikal Abu Dzar Al Ghifari yang menceritakan kisah heroik tokoh dimasa Rosulullah Muhammad SAW. Melalui analisis tersebut akan dihasilkan spektrum estetika Paduan Suara dalam Drama Musikal.
\end{abstract}

Kata kunci: estetika, paduan suara, drama musikal 


\section{PENDAHULUAN}

Perkembangan drama musikal dimulai dari Yunani, dimulai pada abad V BC koor terdiri dari 12 anggota, kemudian olah Sophocles ditambah menjadi 15 orang, musik dan tari Yunani klasik yang tampil dalam pementasan melukiskan etika dan estetika yang mendukung keagungan dan moral yang luhur. Semua konvensi dalam teater Yunani menunjukan suatu perancangan yang sangat canggih. (Yudiariani, 1999:54), di Yunani aktor hanya dibagi kedalam empat kategori: aktor, Figuran dan pemain musik. Semua laki-laki. Dalam tragedi Yunani, hanya ada tiga aktor bagi setiap penulis drama yang diizinkan untuk menggunakan suara mereka sendiri, itupun memerlukan izin khusus. Aktor haruslah seorang seniman dan memiliki keterampilan tinggi. Dialog harus dideklamasikan dengan khusuk, ade dialog dalam adegan yang keras dan ekspresi emosi tinggi, serta beberapa bait lirik tertentu yang harus dinyanyikan dengan iringan pemain suling. Aktor selalu memakai topeng yang lebih besar dari mukanya, dan cirri-ciri dibuat berlebihan, menekankan bentuk dan warna. Dalam drama musikal Abu Dzar Al Ghifari penakanan pada make up karakter yang kuat. Peran Paduan Suara memiliki kemampuan ganda yaitu keahlian akting dan menyanyi berkelompok dengan baik. Pemilihan paduan suara perlu memperhatikan kebutuhan karekter yang terdapat pada naskah. Walaupun dalam naskah Drama Musikal Abu Dzar Al Ghifari Peran Paduan Suara merangkap sebagai penduduk, sebagai para pedagang dipasar, sebagai prajurit, sebagai dinding dan sebagai penari untuk menunjukan pergantian suasana, transisi adegan dan sebagai pendukung tokoh antagonis dengan menunjukan dukungannya melalui lagu dinyanyikan panduan suara. Peran ganda paduan suara memerlukan intensitas berlatih lebih, sebab paduan suara dalam dalam Drama Musika Abu Dzar Al Ghifari ini akan memaksimalkan konsentrasinya untuk melakukan proses tarnsisi pergantianpergantian. Hal ini membutuhkan peran sutradara, penata gerak dan penata suarauntuk mengkonstruksi pemain paduan suara agar dapat menampilkan konfigurasi estetis.

Pertunjukan ditentukan bagaimana sutradara dapat menjadi pemimpin dan dapat mengatur segala sesuatunya dengan baik dan detail, baik ketika sebelum pelaksanaan atau sesudah pelaksanaan, namun sebenarnya yang menentukan berhasil atau tidaknya adalah pada tahap pra penciptaan, sebab dalam sebuah pertunjukan Drama Musikal Abu Dzar Al Ghifari sebagai pertunjukan kolosal, jika sutradara tidak memiliki kreatifitas lebih dalam merancang dan menciptakan maka sedikit hasil bagus yang dapat diperoleh. Namun, sutradara tidak meneruskan langkahnya sendiri, perlu adanya rekan dalam penciptaan kekaryaan tersebut, rekan yang dipilihnya ialah penata suara, penata gerak, penata busana, penata musik, penata lampu, penata setting, dan penata Property, kemudian melakukan diskusi untuk mensosialisasikan bentuk karya kolosal ini, karena belum pernah ada di UNESA pada khususnya dan Jawa Timur pada umumnya sehingga sutradara harus dapat menentukan bentuk Drama Musikal yang akan dikerjakan kemudian proses yang akan dilakukan meliputi apa saja. hal itu di analisis melalui pendekatan Drama Musikal yang akan diciptakan. Nilai lebih Drama Musikal ini selain pada bentuk pertunjukan secara utuh. Paduan suara dalam Drama Musikal Al Ghifari menjadi elemen inti kedua setelah aktor utama yaitu Abu Dzar Al Ghifari.

Estetika paduan suara perlu dibangun berdasarkan proses latihan dengan berpedoman pada naskah Drama Musikal yang diberikan. Selanjutnya tim paduan suara akan melakuan eskplorasi secara mendapam dengan Sutradara untuk memaksimalkan potensi akting, Penata gerak untuk membentuk koreografi dengan pedoman cerita yang terdapat dalam naskah drama dan penata suara sebagai koordinator utama setelah sutradara untuk membentuk kualitas vokal dalam bernyanyi agar suara yang dihasilkan sesuai dengan keinginan sutradara dan kebutuhan naskah yang berdasarkan bentuk pertunjukannya yaitu Drama Musikal bernuansa Arab. Proses eksplorasi ini membutuhkan waktu lama sebab konsentrasi tim paduan suara dan kerjasama tim paduan suara dibentuk dengan baik. Estetika Akting, Estetika Suara dan Estetika gerak menjadi variabel utama dalam kajian Estetika Paduan Suara Drama Musikal Abu Dzar Al Ghifari.

\section{METODE}

Abu Dzar Al Ghifari adalah naskah lakon Drama Musikal karya Agung Waskito naskah ini di perbaharui pada pementasam di Pesantren, Gontor Ponorogo. Ini adalah naskah panggung yang nantinya bisa dipentaskan di atas panggung dengan memperhatikan kaidah-kaidah dramaturgi, teori-teori pertunjukan teater dan teknik paduan suara drama musikal yang sedang berkembang. Dalam memvisualisasikan sebuah 
teks dibutuhkan seorang kordinator atau pemimpin yang tugasnya mengarahkan para anggota (aktor dan kru teknik) dalam memproses teks tersebut.

\section{Tipe Karya}

Pada proses kekaryaan kali ini penulis akan menyelesaikan studi ini dengan menjadi seorang Sutradara, penulias akan menyutradarai naskah lakon Drama Musikal Abu Dzar Al Ghifari karya Agung Waskito. Naskah lakon Drama Musikal ini akan di pentaskan dengan bentuk Paduan Suara Drama Musikal dengan diawali dengan bentuk paduan suara pertunjukan Drama Musikal dengan konvensi Non Realistik. Penciptaan pertunjukan ini berdasarkan teori dramaturgi yang akan dikembangkan penulis menurut kondisi lapangan saat proses kreatif berlangsung.

\section{Gaya}

Dalam naskah lakon drama musikal Abu Dzar Al Ghifari ini dengan teknik penyutradaraan menitik beratkan pada pola permainan aktor pada pola prilaku masyarakat Arab baik itu dari pembawaan gerak ataupun ekspresi, sedangkan untuk penggunaaan bahasa yang hubungannya dengan dialek, didalam pertunjukan nantinya penulis (sutradara) menerapkan dialek bahasa Indonesia baku pada pencapaian aktornya karena jika memakai bentuk dialek Arab maka pembentukan intonasi, artikulasi dan diksi didalam pencapaian karekter, pembentukanya yang tidak mudah.

\section{HASIL DAN PEMBAHASAN}

\section{Dimensi Peran Paduan Suara}

Paduan Suara dalam Drama Musikal Abu Dzar Al Ghifari memiliki dimensi peran paduan suara yang menjadi pendukung sentral sebagai aktor atau peran pendukung. Dimensi peran Paduan Suara Drama Musikal Abu Dzar Al Ghifari terdiri dari. 1) paduan suara sebagai aktor, 2) paduan suara sebagai penguat peristiwa, 3) paduan suara sebagai penonton ideal, 4) paduan suara dan gerak tari. Spektrum tersebut menjadikan Peran Drama Musikal Abu Dzar Al Ghifari dapat menguatkan pertunjukan drama musikal tersebut.

\section{Paduan Suara Sebagai Aktor}

Paduan Suara mewakili opini, memberikan nasehat bahkan terkadang koor mencampuri adegan-adegan dalam pertunjukan. Biasanya koor berada dipihak tokoh protagonistik (Yokoh utama yang menggerakkan plot (alur cerita) dari awal sampai akhir dan memiliki itukad, namun dihalangi oleh tokoh lain, protagonist memiliki irama tragis dan menggerakkan tokoh ( Rikrik El
Saptaria 2006: 34)). Dalam sebuah dialog para penduduk yang juga sebagai paduan suara Drama Musikal Abu Dzar Al Ghifari adalah:

Kelompok Pandu Laku serentak berteriak-teriak mencegah.

\section{KELOMPOK PANDU LAKU:}

Jangan lakukan, Abu Dzar! Menegakkan kebenar-an tidak harus dengan kekerasan! Membela hak pribadi tidak harus melawan kekuasaan! Sarungkan pedangmu! Kekerasan tidak akan bisa menyelesaikan persoalan!

Serentak Para Penduduk Damsyik menghampiri Abu Dzar.

\section{PARA PENDUDUK DAMSYIK:}

Bicaralah, Abu Dzar...! Bicaralah! Bicaralah, sahabat Rasululloh...! Bicaralah menentang kemungkaran! Bicaralah....!! (Dst...)

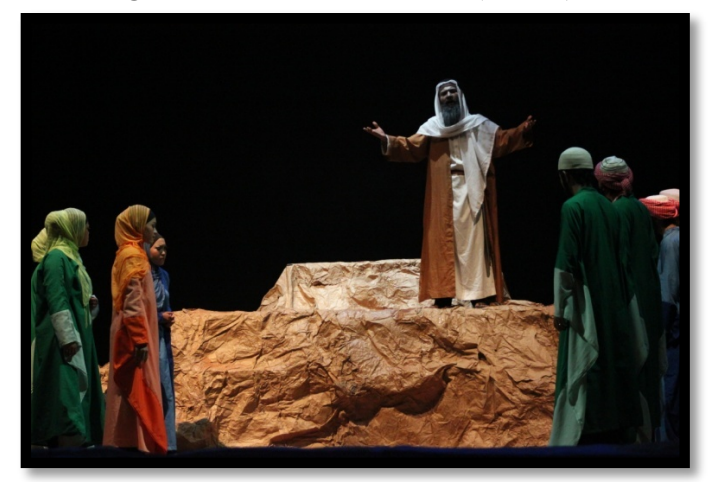

Paduan Suara sebagai penduduk pada pementasan Drama Musikal Abu Dzar Al Ghifari Karya agung Waskito Sutradara Welly Suryandoko

al gifahri

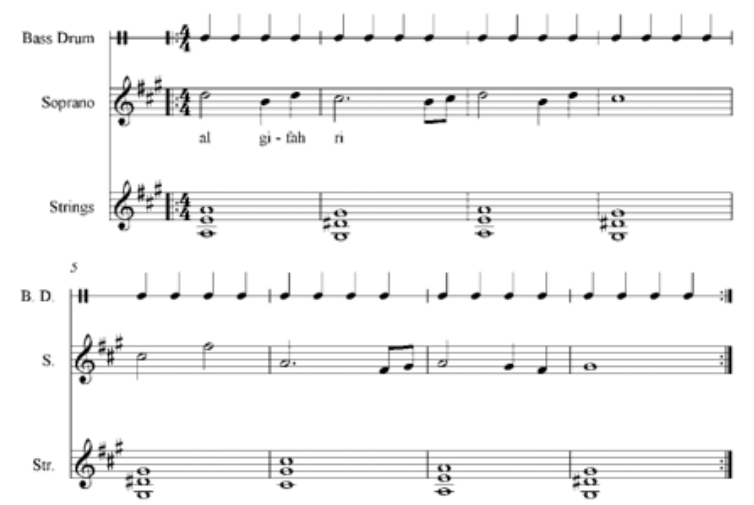




\section{Paduan Suara Sebagai Penguat Peristiwa}

Paduan Suara menentukan kerangka etis (Etika, susila, dan kepantasan (suatu pementasan). Padua suara Drama musikal Abu Dzar Al Ghifari memberikan kesan opening dalam sebuah kerangkah etis dengan memberiakan bentuk konfigurasi Allah. Gambar sebagi berikut:

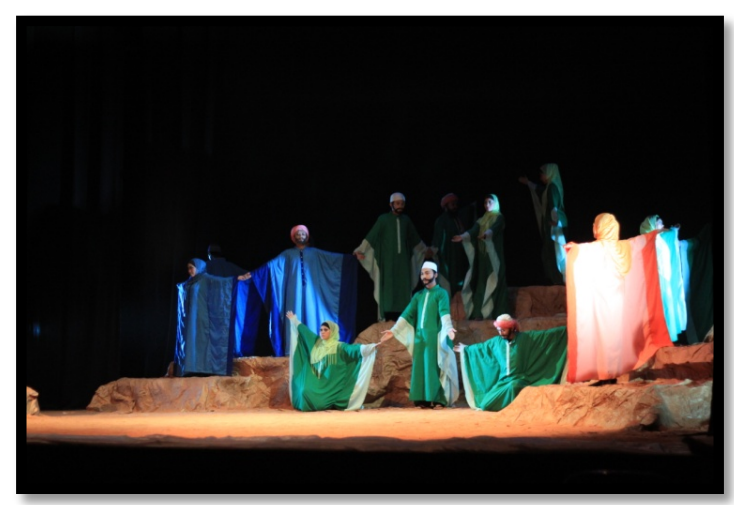

Komposisi bentuk Allah pada pementasan Drama Musikal Abu Dzar Al Ghifari Karya agung Waskito Sutradara Welly Suryandoko

\section{Paduan Suara Sebagai Penonton Ideal}

Paduan Suara berfungsi sebagai penonton yang ideal. Koor bereaksi terhadap adegan-adegan dan terhadap karakter tokoh. Reaksi ini merupakan gambaran yang diinginkan pengarang terhadap reaksi penonton. Suasana pasar yang nampak ramai dengan lalu lalang aktivitas pasar kemudian muncul tokoh Zaid dan Marwan dengan pertikaian kecil, para penduduk berfungsi sebagai penonton dengan melakukan reaksi terhadap adegan-adegan terhadap Zaid dan Marwan. Gambar sebagai berikut:

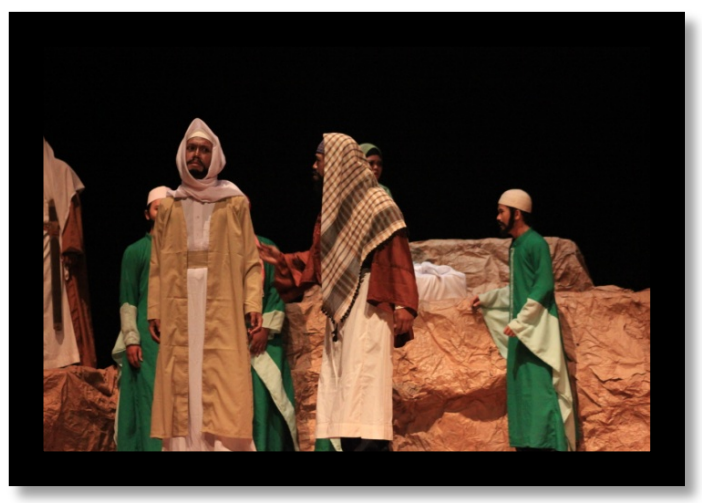

Zaid dan Marwan bertikai dalam pementasan Drama Musikal Abu Dzar Al Ghifari Karya Agung Waskito Sutradara Welly Suryandoko.

\section{Paduan Suara dan Gerak Tari}

membantu menghidupkan suasana hingga mencapai adegan klimaks dan adegan-adegan yang sangat dramatis. Paduan suara saat menyanyikan lagu Al Ghifari memberikan makna gerak semangat Abu Dzar untuk menentang keras setiap kemungkaran dan kedhloliman apapun dan kapanpun. Juga memberikan dapat memberikan kekuatan pada stuktur dramatik

\section{PADUAN SUARA:}

Al Ghifari menggenggam bara api

Abu Dzar melemparkan jangkar

Hari-hari sekonyong terhenti

Yang ingkar terpaku gemetar

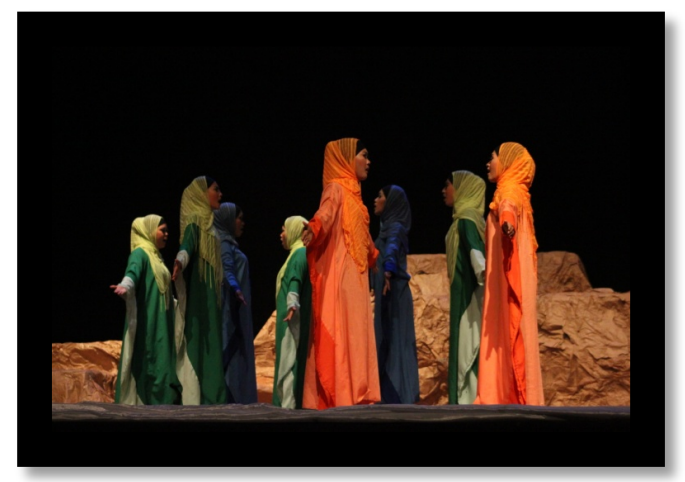

Lagu Al Ghifari dalam pementasan Drama Musikal Abu Dzar Al Ghifari Karya Agung Waskito Sutradara Welly Suryandoko

Paduan Suara dapat menghadirkan suasana melalui gerakan, tari dan nyanyi yang kesemuanya itu memberikan suasan dingin dan tontonan yang menarik. Pada bagian opening nampak dingin namun suasana yang ditimbulkan terhanyut kesebuah doa yang dalam ialah pada lagu Bismillah.

\section{SOLOIS:}

Bismillah alam semesta

Bismillah darah manusia

Bismillah jiwa rindu

Bismillah aku mencarimu

Bismillah sakitku

Bismillah Tuhan janjiku

Bismillah matahari

Bismillah...

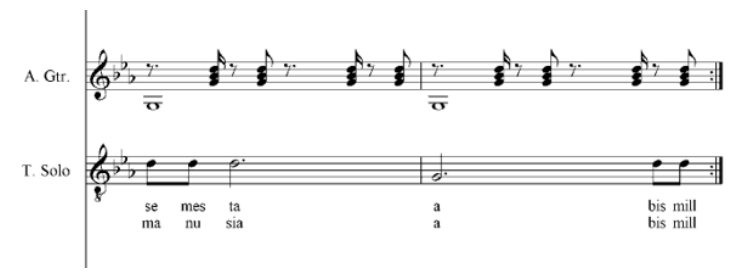


Selain itu juga terdapat pada bagian lagu Terkisahlah, Nampak sekali kekhusyukan paduan suara saat menyanyikan lagu yang berisi tentang eksposisi Abu Dzar Al Ghifari, pada salah satu bagian berisi doa dan semangat Abu Dzar Al Ghifari.

\section{Terkisahlah Abu Dzar Al} Ghifari

Sahabat Rasululloh yang berani

Dia pejalan kaki seorang diri

Dia meninggal seorang diri

Kelak dibangkitkan seorang diri

terkisahlah

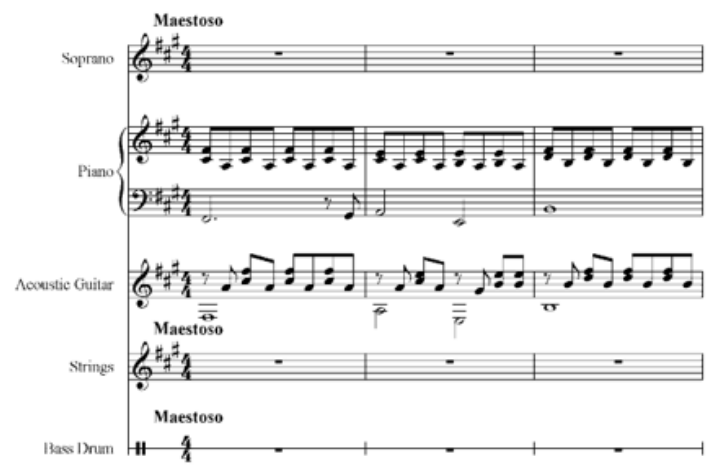

\section{PADUAN SUARA:}

Dari pemuka suku Ghifar yang liar

Tersadar ia akan kebenaran

Tuhan

\section{SOLOIS:}

Seorang diri dia berjalan kaki

\section{PADUAN SUARA:}

Demi meneguhkan kebenaran Islam

Diteriakkannya dua kalimah syahadat

\section{SOLOIS:}

Di tengah kebodohan kaum Quraysi kafir

\section{Estetika paduan suara}

Bentuk paduan suara secara umum adalah kelompok penyanyi baik sejenismaupun campuran (mixed). Sejenis artinya terdiri dari wanita atau pria saja (homogen), atau campuran pria dan wanita (heterogen) dengan kelompok usia yang dikehendaki, atau kelompok anak-anak, remaja, dewasa, hingga orang tua.

Menurut Soedarsono, secara garis besar seni musik, tari maupun teater memiliki tiga fungsi utama (primer) yaitu (1) Sebagai sarana upacara atau ritual; (2) Sebagai hiburan pribadi, dan; (3) Sebagai penyajian estetis. Dilihat dari bentuk pagelarannya, paduan suara dapat berfungsi sebagai sarana upacara ataupun sebagai penyajian estetis. Demensi estetika terbagi menjadi lima hal 1) solois dalam paduan suara, 2) lagu pembuka paduan suara, 3) lagu adengan suasana, 4) lagu klimaks, dan 5) lagu penutup drama musikal.

\section{Solois Dalam Paduan Suara}

Solois Diperankan oleh Noval Dwi Cahyo guru sekolah anak Indonesia di Malaysia berasal dari Kalimantan namun sekarang bertempat tinggal di Malaysia, sebagai seorang paduan suara pada bagian soloisnya, sutradara memilih noval karena selain melakukan kekaryaaan akhir bersama dengan Vokal, selain itu juga suara yang bagus, bentuk tubuh yang tinggi yang dapat mendukung paduan suara agar dapat lebih terlihat dan menjadi fokus. Nuansa musik Arab dalam pementasan Drama Musikal Abu Dzar Al Ghifari ini ditonjolkan walaupun tidak murni bentuk musik Arab, karena lagu paduan suara yang dinyanyikan terkesan ngepop sehingga bentuk musik nuansa arab ditonjolkan.

Seseorang akan melihat ciri khusus seorang selain dari tubuh adalah dari cara berbicara/berdialog, oleh karena itu penonjolan ciri dari dialog pemain perlu diasa semaksimal mungkin, baik eksplorasi pemain drama dengan paduan suara yang tentu proses eksplorasi vokal yang berbeda, proses olah vokal pemain drama adalah dengan pembentukan produksi vokal yang benar yang tujuannya agar ketika berdialog diatas panggung pemain tidak lelah saat berdialog karena produksi vokal yang kurang tepat, kemudian pembentukan artikulasi yaitu kejelasan ucap pada kalimat yang hubungannya dengan komunikasi dengan pemain lain,dan dengan penonton, selain itu yang dilakukan adalah proses membentuk intonasi yaitu dapat memberikan maksud, variasi dan irama dalam dialog sehingga lebih bisa didapatkan makna dari dialog yang disampaikan. Sedangkan untuk olah vokal untuk paduan suara adalah pada penguasaan pencapaian tangga nada. 


\section{Lagu Pembuka Paduan Suara}

\section{"Lagu Bismillah" \\ SOLOIS:}

Bismillah alam semesta

Bismillah darah manusia

Bismillah jiwa rindu

Bismillah aku mencarimu

Bismillah sakitku

Bismillah Tuhan janjiku

Bismillah matahari

Bismillah...

Paduan Suara menimpalinya dalam koor.

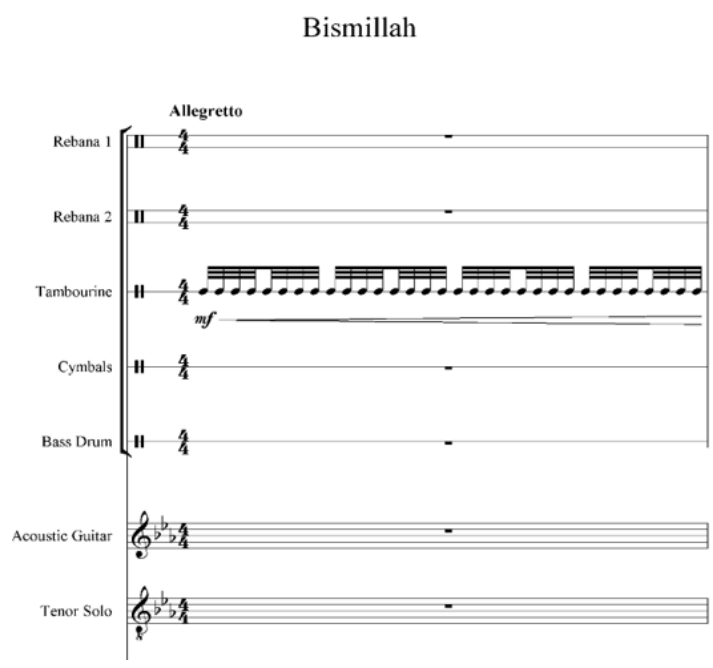

\section{Lagu Adegan Suasana}

\section{"Lagu Berduyun-duyun"}

\section{PADUAN SUARA:}

Berduyun-duyun penduduk Damsyik berkumpul

Pada Abu Dzar memohon pertimbangan

Tegarlah jiwa menyeru kebenaran

Saatnya tiba membawa amanah Tuhan

Jiwa perwira pantang undur juan

Demi Tuhannya....

\section{"Lagu Tak Akan Pernah"}

\section{KELOMPOK PANDU LAKU:}

Tak akan pernah dijumpai lagi

Orang yang benar ucapannya

Selain Abu Dzar Al Ghifari

Ketika menyuarakan kebenaran Tuhan

Ia ditentang dan dimusuhi

Meninggal ia di jalan Ilahi

Di gurun Rabadzah yang sunyi

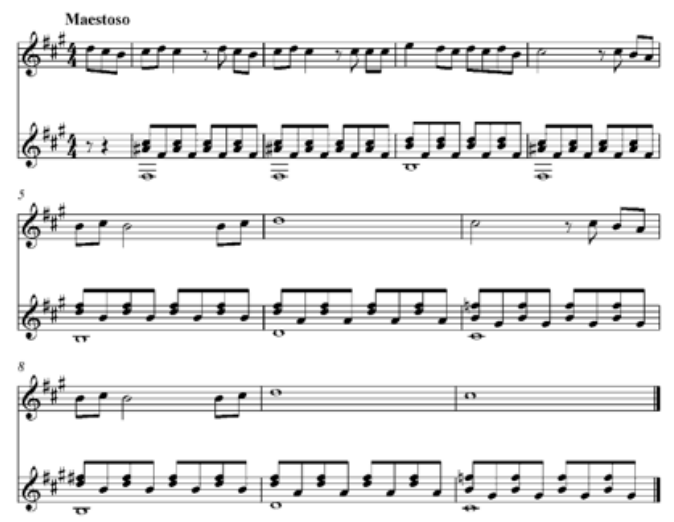

\section{Lagu Klimaks}

\section{"Lagu Harta Bilangan Pasir" SOLOIS:}

Harta itu hanya bilangan pasir Selama ada dalam simpanan Barulah terang nilai harganya

Kalau telah lepas dari dalam tangan

Matahari tetap kan bersinar Hasrat hati tak pernah padam Semesta goda menghampiri Lawanlah dengan taqwa pada Tuhan

\section{PADUAN SUARA:}

Kita jelang cahaya benderang Menahan diri dengan sembahyang Sebab hidup ini ujian Sampai datang pengadilan Tuhan

Terlaknat yang menuhankan harta

Dia diperbudak oleh benda

Tawaran peradaban

Bagaikan berjuta berhala

Tabah hati menjalani

Segera tiba kemenangan

Tabahkan hati menjalani...

Segera tiba kemanangan...

Tabahkan hati menjalani...

Segera tiba kemenangan... (dst 
harta itu bilangan pasir

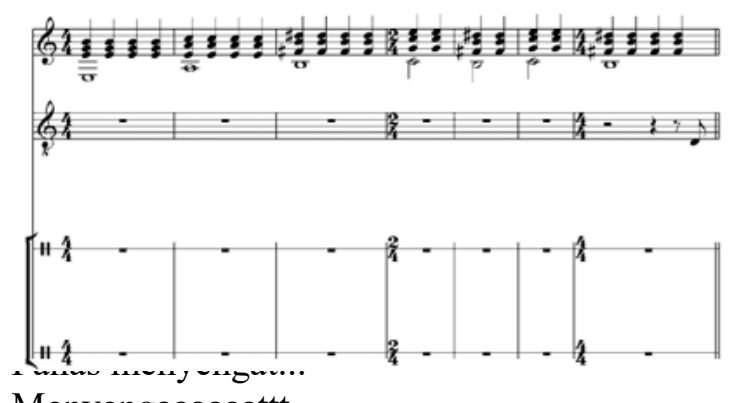

Menyengaaaaaattt....

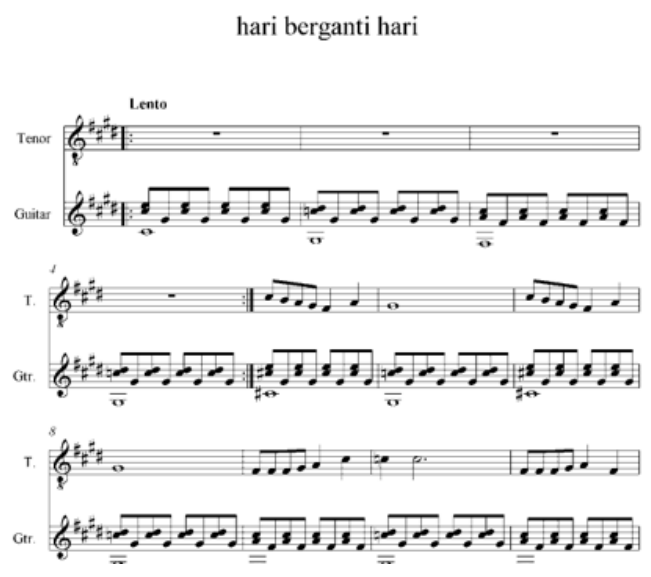

\section{PENUTUP}

Kerja Paduan Suara Drama Musikal adalah kerja yang tidak mudah, membutuhkan tenaga ekstra dan membutuhkan keikhlasan bagi yang menjalaninya, keran dalam proses Drama Musikal Abu Dzar Al Ghifari ini menekankan pada niat terlebih dahulu sehingga rutinitas eksplorasi dapat berjalan dengan baik dan sesuai dengan target yang dikehendaki, kemudian ikhlas, yaitu ikhlas dalam menjalankan segala rutinitas yang berjalan selama empat bulan, dalam pencapaian teknik pun dapat di transformasikan sesuai dengan perpaduan ketiga teknik dengan formulasi teknik baru yang didapatkan dari ketiga teknik tersebut walaupun terkadang kebosanan sesekali muncul dalam diri aktor sehingga proses eksplorasi kadang tidak berjalan maksimal, karena sesungguhnya yang menyesuaikan tidak selamanya dari sutradara aktorpun harus bisa menyesuaikan rutinitas latihan dengan membawa suasana latihan yang kembali cair, selain itu drama musikal adalah pertunjukan kolosal yang membutuhkan rutinitas latihan dengan jumlah aktor yang dapat sesuai setiap kali latihan karena membutuhkan penyesuaian dan ketepatan dalam gerak dan paduan suara, hal tersebut berhubungan dengan aksi dan emosi yang harus terus terjalin. Dari hasil kesimpulan diatas pula perlu dijadikan pelajar bagi sutradara dan pembaca dalam menciptakan sebuah pertunjukan kolosal yang paling utama adalah sabat, tidak gegabah, detail dan jujur dalam menentukan bentuk

memberikan gambaran serta tawaran pembelajaran pendidikan musik yang efisien di sekolah umum pada negara-negara berkembang.

\section{DAFTAR PUSTAKA}

El Saptaria, Rikrik. 2006. Panduan Praktis Akting untuk Film dan Teater. Bandung: Rekayasa Sains.

Hestyono, M. 1997. Sekelumit Tentang Paduan Suara. Bandung: Tidak diterbitkan.

Jamalus. 1991. Pendidikan Kesenian I (Musik). Jakarta: Bumi Aksara.

Joseph, Wagiman. 2004. Teori Musik II. Semarang : Sendratasik, FBS, UNNES.

Kurnianingsih, Widhi. 2013. Pembelajaran Vokal di Purwacaraka Musik Studio Semarang. Semarang: Tidak diterbitkan

Riantiarno, N, 2003, Menyentuh Teater, MU:3 Books, Jakarta

Sahid, Nur, 2004, Semiotika teater, Lembaga penelitian ISI Yogyakarta.

Soedarsono, RM. 1972. Djawa Dan Bali DuaPusatPerkembanganSeni

Drama Tradisional Di Indonesia.Yogyakarta: Gajah Mada University Press.

Yudiarini, M.A Drs; 2002.Panggung Teater Dunia. Pustaka Gendho Suli. Jogjakarta. 